\title{
ESBOZO DE CUATRO REGLAS SOBRE LA VOLUNTARIEDAD DEL DESISTIMIENTO DE LA TENTATIVA*
}

\author{
Jorge C. Restrepo Ramos*
}

\begin{abstract}
Resumen: El presente trabajo, tras hacer una explicación general de la figura jurídica del desistimiento de la tentativa delictiva y, concretamente, del requisito de la voluntariedad que debe cumplir para ser válida, problematiza algunos puntos centrales de la teoría del desistimiento. Adicionalmente, el trabajo presenta (sin elaborar una teoría sistemática y omnicomprensiva sobre el tema en cuestión) algunos topoi que no pueden perderse de vista a la hora de dar solución a los casos difíciles de tentativa desistida. A manera de conclusión, los topoi son sistematizados en la forma de cuatro reglas que se deducen de tres pilares político-criminales del Derecho penal colombiano, a saber: el principio de legalidad, el uso de amenazas como método disuasorio por parte de la ley y el Derecho penal de acto.
\end{abstract}

\footnotetext{
La primera parte de este escrito fue elaborada mientras trabajaba para la oficina de abogados del Profesor Miguel CóRdoba Angulo. Durante dicha etapa, recibí orientación e importantes críticas de su parte sobre el texto, por las cuales estoy altamente agradecido. Soy el único responsable, sobra decirlo, de todos los yerros y defectos de este trabajo. Fecha de recepción: 27 de enero de 2016. Fecha de modificación: 29 de enero de 2016. Fecha de aceptación: 31 de enero de 2016. Para citar el artículo: Restrepo RAmos, JoRge C. (2015). "Esbozo de cuatros reglas sobre la voluntariedad del desistimiento de la tentativa", Revista Derecho Penal y Criminología, Vol. 37, n. ${ }^{\circ}$ 101, juliodiciembre de 2015. Bogotá: Universidad Externado de Colombia, pp. 153-179. DOI: http://dx.doi. org/10.18601/ 01210483.v36n101.06

** Abogado (Universidad Externado de Colombia), Magíster en Filosofía (Universidad de los Andes), actualmente candidato a PhD del grupo de Filosofía del Derecho de la Universidad de Tilburgo (Países Bajos). El autor ha sido profesor de Introducción al Derecho (Universidad del Rosario) y Teoría del Derecho (Universidad Católica de Colombia). Bogotá, D.C.,Colombia.Correo-e: J.C.RestrepoRamos@uvt.nl.
} 
Palabras clave: Desistimiento; Voluntariedad; Tentativa.

\title{
A SKETCH OF FOUR RULES ON THE VOLUNTARY CHARACTER OF THE ABANDONMENT OF CRIMINAL ATTEMPT
}

\begin{abstract}
Summary: After putting forward a general explanation of the legal concept of abandonment of criminal attempt and its requirement of voluntariness, this paper points out certain critical points of the theory of abandonment. Furthermore, the paper presents (without aiming at building a systematic and comprehensive theory) some topoi that cannot be overlooked when solving difficult cases of abandonment. In conclusion, the referred topoi are systematized in the form of four rules that are deducted from two criminal-political principles of Colombian criminal law, i.e., the principle of legality and the use of threats as a dissuasive method by the law and the offense-based character of criminal law.
\end{abstract}

Keywords: Abandonment; Voluntariness; Criminal Attempt; Rules of Abandonment.

\section{INTRODUCCIÓN}

El desistimiento de la tentativa es una figura jurídica que se presenta cuando el agente de un delito, tras comenzar los actos de ejecución del mismo, voluntariamente impide con éxito que se produzca el resultado delictivo inicialmente planeado, ya sea interrumpiendo su ejecución en los casos de tentativa inacabada, o contrarrestando los actos ya ejecutados tratándose de tentativa acabada ${ }^{1}$. De acuerdo con esta institución, la serie de actos ejecutivos constitutivos de la tipicidad de un delito en grado de tentativa quedarían impunes -a menos que, en sí mismos, constituyan algún delito consumado y no solo los actos ejecutivos del delito inicialmente tentado (delito remanente)-, si el sujeto activo detiene voluntariamente el proceso ejecutivo del delito o deshace los actos ya ejecutados de una tentativa acabada.

Alrededor de esta figura surgen varios interrogantes, entre ellos, los siguientes: ¿por qué, salvo la punición de los delitos remanentes, no hay reacción alguna por parte del ordenamiento jurídico en los casos de desistimiento? ¿Qué categoría dogmáti-

1 “.... pesar de haber dado comienzo a los actos de ejecución -esto es, aquellos que demarcan o delimitan el campo entre lo que está permitido y lo que está prohibido en materia penal, y con los cuales el delito está ya tentado-, voluntariamente, por sí mismo, impide que se produzca el resultado en un comienzo querido, para lo cual basta con la simple o mera interrupción de su propósito criminal en el caso de la tentativa simple o inacabada, ora mediante un hacer que contrarreste, anule o enerve lo realizado en tratándose de la denominada tentativa concluida o acabada" (ARAQUE MoRENO, 2008, p. 23). 
ca del delito o de los requisitos de punibilidad se anula por su acaecimiento? ¿Qué requisitos deben constatarse para que una tentativa delictiva se estime desistida? A continuación se presenta, en términos muy generales, la manera en la que la doctrina ha abordado estas preguntas, con el objeto de ofrecer ciertos lineamientos preliminares que podrían ser útiles a la hora de determinar si un acto de desistimiento ha sido efectivamente "voluntario" (uno de los requisitos del desistimiento válido) y, por ello, capaz de conllevar la no punición de la tentativa delictiva (numerales I a III).

Vale la pena aclarar que el recorrido doctrinal aquí presentado no pretende ser, ni en lo más remoto, exhaustivo de la extensa literatura que existe sobre este tema ${ }^{2}$. Igualmente, las consideraciones de fondo que se harán sobre la voluntariedad del desistimiento tampoco son capaces de dar una respuesta satisfactoria para todos los muchos casos que se pueden presentar. Este trabajo tiene una pretensión mucho más modesta: problematizar ciertos puntos medulares de la teoría del desistimiento para ofrecer ciertos topoi que no pueden perderse de vista a la hora de ofrecer soluciones a los casos difíciles de tentativa desistida, sin pretender, en manera alguna, elaborar una teoría consistente y omnicomprensiva sobre el requisito de la voluntariedad (numeral IV).

\section{FUNDAMENTO DE LA NO PUNICIÓN DE LA TENTATIVA DESISTIDA}

De acuerdo con el dispositivo amplificador de la tentativa, regulado en el artículo 27 del Código Penal, son punibles los actos ejecutivos de un delito que, pese a estar encaminados dolosamente a su consumación, son frustrados por una causa ajena al agente. Ahora bien, si el agente es la causa voluntaria de esa frustración delictiva y los actos ejecutivos en cuestión no constituyen ningún delito consumado, no hay lugar a punición. ¿En qué radica ese tratamiento jurídico? Existen fundamentalmente dos tipos de teorías para sustentar la impunidad de la tentativa desistida, a saber, las teorías jurídicas y las teorías político-criminales. El primer grupo de teorías sostiene que el desistimiento no es punible por razones sistemático-dogmáticas, es decir, porque la presencia del desistimiento anula la configuración de la conducta punible en cuestión y, en consecuencia, no hay lugar a imponer ninguna sanción; el segundo grupo considera, en cambio, que la no punición de la tentativa desistida radica en que el legislador, de manera discrecional y en ejercicio de sus potestades directivas

2 El trabajo más completo sobre el desistimiento en nuestro medio del que tengo conocimiento es DIEGO ARAQue Moreno (Op. cit.), cuya exposición sirvió de referencia a buena parte del trabajo preliminar de este texto. Igualmente ilustrativo resulta FranCISCO MuÑoz CONDE (1972). 
de la política criminal estatal, ha optado por no sancionar estos eventos. Este último tipo de teorías es actualmente el de mayor aceptación doctrinal ${ }^{3}$.

Puesto que las teorías jurídicas implican que el delito no se configura, las mismas suponen una causal de ausencia de alguna de las categorías dogmáticas del delito, por lo que serán tratadas más adelante, al abordar el escaño sistemático propio de esta figura. En lo que corresponde al otro grupo de teorías, es menester mencionar las siguientes:

1. Teoría del premio. De acuerdo con esta teoría, el legislador pretende "premiar" con la impunidad el comportamiento de quien desiste de llevar a feliz término el delito cuya ejecución ha iniciado. Esta teoría se compagina con comprender que el carácter lesivo de la tentativa radica en la impresión social, como se aprecia en la defensa que de la misma hacen autores como ZAFFARONI ${ }^{4}$, JESCHECK $^{5}$ y MAURACH $^{6}$, y que, por lo tanto, es digno de recompensa el comportamiento encaminado a eliminar la "lesión" que la impresión genera en la sociedad.

A esta teoría se le critica incurrir en una petición de principio, pues en vez de dar explicación sobre la razón que tiene el legislador para no sancionar el desistimiento, se limita a reiterar que el desistimiento no es punible ${ }^{7}$. Igualmente, resulta censurable otorgar una misión "premial" al derecho penal, en especial cuando se entiende que

3 “... la Ciencia se ha venido ocupando siempre de la justificación de la impunidad del desistimiento voluntario de la tentativa. Las antiguas (así denominadas) “teorías jurídicas" que quisieron ver en el desistimiento un obstáculo jurídico para el castigo de la tentativa (Zachariä, Luden, Berner, Binding) hoy apenas son defendidas. No son, pues, motivos derivados de la lógica jurídica sino razones provenientes de la discrecionalidad legislativa las que actualmente son resaltadas para la justificación de la impunidad de la tentativa en caso de desistimiento de la misma. La cuestión de cuáles sean estos motivos no posee sólo un significado teórico sino que tiene un alcance práctico sobre todo en la determinación del concepto de "voluntariedad"” (JESCHECK, et al., 2002, p. 578).

4 "En nuestro concepto, la impunidad del desistimiento no puede tener otro sentido que el de una renuncia hecha por el derecho en razón de que el mismo hace desaparecer el peligro creado por la tentativa y, al mismo tiempo, cancela en el caso concreto la impresión amenazadora que la tentativa presenta" (ZAFFARONI. 1982, p. 483). Este mismo autor critica ciertas formas de la teoría premial en ZAFFARONI et al. (2002, p. 840).

5 "Quien desiste voluntariamente y evita la consumación o se esfuerza seriamente en ello aún (sic) cuando de todos modos aquélla tiene lugar, en la comunidad se compensa parcialmente la impresión jurídicamente perturbadora de su hecho y, a causa de ello, merece indulgencia" (JESCHECK. Op. cit., p. 579).

6 "Si el motivo de la penalidad de la tentativa está dado por el efecto conmovedor del derecho provocado por el autor, así el motivo del privilegio de la liberación de la pena sólo puede ser visto en la eliminación de ese mismo efecto" (MaURACH et al., 1995, p. 73).

7 'Es cierto que el desistimiento voluntario es 'recompensado' con la impunidad; pero esa afirmación sólo contiene una transcripción de lo que de todos modos está en la ley. La cuestión decisiva es por qué 'recompensa' de ese modo el legislador el desistimiento voluntario y por qué depara la 'gracia' de la impunidad al autor de la tentativa" (Roxin, 1976). En el mismo sentido, GÜNTER STRATENWERTH (s.f., p. 219). 
los delitos remanentes en el caso del desistimiento - es decir, las conductas punibles que se consuman en el proceso ejecutivo del delito, con anterioridad al retroceso del agente- siguen siendo punibles, incluso siendo más graves que el delito desistido ${ }^{8}$. 2. Puente de plata o puente de oro. Esta teoría, que se remonta a FEUERBACH, fue formulada por V. LiszT en los siguientes términos: "En el momento en que se traspasa la línea divisoria entre los actos preparatorios impunes y la ejecución punible, se incurre en la pena establecida para la tentativa. Este hecho no puede ser ya alterado, ni 'anulado por volverse atrás', ni desaparecer del mundo. Sin embargo, puede la legislación, por razones de Política criminal, construir un puente de oro para la retirada del agente que ya era susceptible de pena. Ella lo ha hecho, convirtiendo en causa de extinción de la pena el desistimiento espontáneo". Según lo manifestado por este autor, la razón de ser de la impunidad del desistimiento es el estímulo preventivo que el legislador le otorga al delincuente para que, antes de consumar la conducta punible, se retire impunemente de la misma. Esta doctrina tuvo un eco considerable entre muchos juristas de distintos países ${ }^{10}$.

A esta teoría se le suele criticar que la impunidad del desistimiento es algo que el agente puede perfectamente desconocer (de hecho, tal desconocimiento parece ser habitual en muchas sociedades); por lo tanto, no puede tomarse en serio que los delincuentes hagan un cálculo de consecuencias entre los beneficios de la consumación y los del supuesto estímulo del puente de oro $^{11}$.

Roxin critica, adicionalmente, que la tesis implica que el desistimiento no requeriría ser eficaz -como lo reconoce la doctrina unánimemente y lo exigen tácitamente legislaciones como la nuestra (vid. art. 27, inc. 2 del CP)- pues bastaría un esfuerzo del agente por evitar el resultado para poder recibir los beneficios de impunidad, en cuanto el incentivo psicológico preventivo sería más poderoso si el esfuerzo ineficaz fuera suficiente ${ }^{12}$.

3. Teoría de la necesidad de pena de Roxin. Para Roxin, en los casos de desistimiento, la pena es plenamente innecesaria, pues no se atiende ninguno de sus fines. Así, dice el mentado autor: "No hay razones de prevención general que reclamen un castigo, porque no se produce el resultado y el autor, al mostrarse fiel al Derecho en el momento decisivo, no da mal ejemplo a nadie. Las influencias de prevención especial

8 Cfr. Francisco Muñoz Conde (Op. cit., p. 29 y ss). Igualmente, Diego Araque Moreno. Op. Cit. p. 46.

9 Franz von Liszt. Tratado de Derecho Penal. V. 3. Madrid, Reus, 1929, p. 20.

10 Vid. referencias en Diego Araque Moreno. Op. Cit. p. 47.

11 Cfr. MAx ERnst MAYER (2007, p. 458, n. 71).

12 "Además la teoría del puente de plata no tiene que exigir necesariamente que se evite el resultado; el incentivo psicológico para el retorno se reforzaría incluso más si los serios esfuerzos por evitar el resultado condujeran ya por sí solos a la impunidad" (Roxin, 1976, p. 268). También en contra de estas explicaciones, pero por razones sistemáticas distintas, GÜNTHER JAKOBS (1997, pp. 327 y 328 ). 
son innecesarias porque con su desistimiento el autor ha vuelto a la legalidad; su eventual inestabilidad, manifestada ya a través de la tentativa, no es por sí sola razón suficiente para imponer sanciones penales si el sujeto renuncia voluntariamente a provocar el resultado. Y la compensación de la culpabilidad parece también superflua porque el mismo autor ha reparado y 'compensado' la culpabilidad que implicaba la tentativa con su voluntario desistimiento” (Roxin, 1976, pp. 266 y 267).

En contra de esta tesis se han elevado distintas críticas. JESCHECK (Op. cit., p. 580) dice que no existen motivos para afirmar la no concurrencia de fines de la pena en muchos eventos que deben encuadrar en la figura del desistimiento; así, por ejemplo, "la voluntad del autor en el momento de la tentativa puede haber sido lo suficientemente intensa para la consumación, pues a menudo el desistimiento es provocado por circunstancias externas puramente azarosas. Por regla general, tampoco la peligrosidad del hecho y del autor se muestran mucho menores a causa del desistimiento. El merecimiento de pena del hecho no es anulado sin más por el desistimiento". Ciertamente, si en el momento concreto del desistimiento el motivo del agente es, verbigracia, reprochable u obedece a un frío cálculo, en tales casos la pena parecería necesaria pero no hay lugar a la imposición de pena alguna.

Roxin ha replicado a esta crítica que para su concepción del desistimiento el requisito de la voluntariedad "exige necesariamente la existencia de un comportamiento que resulte contrario a la 'lógica del delincuente', con arreglo a la cual las circunstancias externas causales o azarosas no pueden per se dar fundamento al efecto principal de la impunidad, ya que lo decisivo, lo que verdadera y realmente importa, es que muy a pesar de la falta de esas circunstancias, el agente no fue capaz de consumar el injusto, optando más bien por interrumpir o abandonar su ejecución" (Roxin, 1976, p. 267). Sobre esta concepción de la voluntariedad se volverá más adelante.

4. Teoría de JAKOBS. Para este autor, los grados de tentativa y consumación son esencialmente idénticos, pues en ambos hay un quebrantamiento normativo merecedor de una sanción restablecedora de la validez de la norma. Ahora bien, para JAKOBS la infracción a la norma acaece cuando el autor "se separa" de su conducta, evento en el cual ya queda realizado el injusto y cualquier consideración ulterior es de carácter posdelictivo. Pero antes de esa separación todavía puede haber desistimiento, pues no ha existido propiamente ningún delito. "Pero ¿cuándo queda separado el autor de su conducta? La respuesta es: siempre que él pierde aunque solo sea una posibilidad de influir sobre el mundo futuro" (JAKOBS, Op. cit., pp. 526 y ss.). La de JAKOBS es una teoría unitaria, en la que se resuelve el tema de manera jurídica y en consonancia plena entre tentativa y desistimiento (es decir, la no configuración de la tentativa acarrea el estado de desistimiento y su correlativa impunidad $)^{13}$.

13 Vid., in extenso, MARCElo A. SANCINETti (1995). 


\section{UBICACIÓN DOGMÁTICA}

Si el desistimiento tiene la virtualidad de eliminar la punición de la tentativa, como ya se explicó, ello debe obedecer a una razón sistemática (es decir, a la eliminación de uno de los tres escaños dogmáticos de la conducta punible) o, como lo sostienen los defensores de las teorías evaluadas con precedencia, a la enervación, por motivos de política criminal, de los presupuestos de la pena o de la configuración misma del delito -entendiendo que las categorías dogmáticas son dependientes de la política criminal, de conformidad con los cánones del derecho penal contemporáneo-. Ahora bien, ¿qué tipo de categoría dogmática se excluiría por parte del desistimiento? Los autores ofrecen las siguientes soluciones.

1. Desistimiento como causal de atipicidad objetiva. Esta tesis, casi unánime en la doctrina colombiana, sostiene que puesto que el dispositivo amplificador de la tentativa exige que la no consumación provenga de un hecho ajeno a la voluntad del delincuente ${ }^{14}$, contrario sensu, la no consumación derivada de su voluntad es atípica. En ese sentido, dice REYES ECHANDÍA que el desistimiento ni siquiera amerita consagración legislativa alguna, pues se trata de un evento que no tipifica ninguna conducta punible, tesis que hizo carrera en la reforma legislativa de 1980 y que se mantiene en el actual Código Penal colombiano (ReYes Echandía, 1981, p. 197) ${ }^{15}$.

2. Desistimiento como causal de atipicidad subjetiva. Algunos autores, usualmente finalistas ortodoxos, consideran que el desistimiento "interrumpe" el perfeccionamiento del dolo: en el desistimiento, "la voluntad de realización subsiste como tal solo hasta el instante que precede a la suspensión de la conducta típica o a la ejecución de la acción destinada a evitar el resultado. Luego los dos componentes dinámicos de la acción típica se detienen simultáneamente. En estas hipótesis, por consiguiente, falta la perfección del dolo y, con eso, la base para castigar el principio de ejecución de la acción descrita por el tipo. No se trata, como algunos autores pensaban en otro tiempo, de una 'cancelación' de la voluntad prexistente, sino de un defecto en su formación, que excluye la tipicidad del comienzo de ejecución porque falta el componente subjetivo sobre el que aquélla descansaba" (CuRY URZÚA, 1992, p. 205).

14 ART. 27. - Tentativa. El que iniciare la ejecución de una conducta punible mediante actos idóneos e inequívocamente dirigidos a su consumación, y ésta no se produjere por circunstancias ajenas a su voluntad, incurrirá en pena no menor de la mitad del mínimo ni mayor de las tres cuartas partes del máximo de la señalada para la conducta punible consumada.

Cuando la conducta punible no se consuma por circunstancias ajenas a la voluntad del autor o partícipe, incurrirá en pena no menor de la tercera parte del mínimo ni mayor de las dos terceras partes del máximo de la señalada para su consumación, si voluntariamente ha realizado todos los esfuerzos necesarios para impedirla (destacado fuera del texto). 
3. Desistimiento como elemento negativo de la antijuridicidad. Para BINDING, quien sostiene que toda ley penal tiene un mandato ínsito (es decir, el imperativo dirigido al ciudadano, diferenciado de la norma penal que, en realidad, se dirigiría al funcionario juzgador), entendía que el desistimiento corresponde a un "cumplimiento" del mandato, lo que implicaría la cesación de la antijuridicidad. Este tipo de tesis presupone una antijuridicidad estructurada subjetivamente, sin lineamientos claros entre injusto y culpabilidad (MuÑoz CONDE, Op. cit. p. 16, 53 y ss; ArAQUE MoreNO, Op. cit. pp. 87 y ss.).

4. Desistimiento como causal de inculpabilidad o circunstancia de culpabilidad insignificante. La ya mencionada tesis de Roxin sobre la ausencia de necesidad de pena en los casos de desistimiento, atendiendo al carácter político-criminal que tiene el juicio de culpabilidad en la doctrina de este autor, implica comprender que el desistimiento elimina la categoría dogmática de la responsabilidad.

Por otro lado, tras haber abandonado la tesis del puente de oro, la cual tilda de "ajena a la vida y contraria al $§ 46$ ", Welzel (1987, p. 271) considera que "El verdadero sentido del privilegio al que se desiste reside en la insignificancia de su culpabilidad, que se muestra en el desistimiento". Desde una perspectiva causalista, SAUER sostiene la misma tesis (1956, p. 183).

A esta última tesis se le pueden hacer extensivas todas las bien conocidas críticas a la teoría normativa de la culpabilidad y, en concreto, debe tenerse en cuenta que en muchas ocasiones los motivos de desistimiento son altamente reprochables y, de hecho, encarnan una culpabilidad superior (ARAQUE MORENO. Op. cit., pp. 58 y ss.).

5. Desistimiento como excusa legal absolutoria. Las teorías político-criminales, en su mayoría, se inclinan a pensar que la configuración del delito en el desistimiento es perfecta, luego su impunidad tendría que radicar más allá de la teoría del delito. En ese sentido, dice v. LiszT (Op. cit., p. 20) que los actos ejecutivos realizados ya implican la pena de la tentativa y que ese acto "no puede ser ya alterado, ni 'anulado por volverse atrás', ni desaparecer del mundo". En el mismo sentido, ZAFFARONI (Op. cit., p. 481) dice que "la principal objeción que puede formulársele al argumento que pretende ver en el desistimiento una atipicidad, sea por atipicidad objetiva o subjetiva, yace con la imposibilidad de que el desistimiento tenga la virtualidad de dejar atípica una conducta que ya era típica. Si el comienzo de ejecución es objetiva y subjetivamente típico, no se comprende cómo un acto posterior pueda eliminar lo que ya se afirmó como prohibido, situación que resulta sumamente parecida a la del consentimiento subsecuente".

En estas circunstancias, sigue el autor argentino, "se hace evidente que la imposibilidad de que una etapa posterior cancele la tipicidad o la culpabilidad que ya han sido afirmadas para una etapa anterior, lleva a buscar la naturaleza del desistimiento 
en una problemática que está fuera de la teoría del delito, es decir, en la teoría de la coerción penal. Se trata, a nuestro juicio, de una causa personal que cancela la punibilidad del delito, pero que no afecta ninguno de sus caracteres, que permanecen completamente inalterados" (ídem, p. 482).

Sin poder profundizar aquí en este punto, vale la pena notar que la supuesta imposibilidad de "echarse para atrás" en la apreciación del carácter delictual de una conducta parece responder a un excesivo naturalismo y a una exageración del substratum de la conducta delictiva y de la idea de "puesta en peligro de un bien jurídico" como acto "imborrable". Por el contrario, en principio nada se opone a que, atendidas todas las circunstancias, se afirme que una conducta en principio delictiva y que, en un momento dado, recorría un tipo penal amplificado por el dispositivo de la tentativa, sea estimada posteriormente como no delictiva al atenerse a todos los datos disponibles. Es cierto que ello implica flexibilizar el carácter categórico de las herramientas dogmáticas, pero no se ve por qué semejante proceder es reprochable y no, más bien, ineludible (a menos que, desde luego, se presupusiera una difícilmente sostenible "esencia delictual" de ciertos comportamientos, a los cuales las categorías dogmáticas solo ofrecerían un nombre).

6. Dependencia de los distintos derechos positivos. Ante este panorama doctrinal, considera con razón ARAQUE MORENO que la ubicación del desistimiento es un problema de lege lata: hay que examinar qué es lo que dicen los derechos positivos de cada caso. Así, en nuestro Código, dada la regulación del 27, estamos ante una "ausencia de antijuridicidad tipificada", mientras que esta solución no encuadra ni en el derecho positivo alemán ni en el español (ARAQue Moreno, Op. cit., pp. 95 y ss.).

\section{LA VOLUNTARIEDAD COMO REQUISITO DEL DESISTIMIENTO VÁLIDO}

La doctrina ha reconocido tradicionalmente que la institución del desistimiento requiere que concurran dos requisitos: en primer lugar, el desistimiento debe ser voluntario, "esto es, debe provenir del sujeto o del mismo actor que ha puesto en marcha el curso causal con dirección inequívoca de consumar el punible, de realizar en su totalidad los elementos que componen el tipo penal" (ídem, p. 107); en segundo lugar, debe ser eficaz, "vale decir, exitoso, en la medida en que el agente logre efectivamente impedir que el resultado inicialmente querido y consecuencia ordinaria de su conducta, se produzca" (REYEs ECHANDía, Op. cit., p. 196).

En lo que concierne al requisito de la voluntariedad, sin embargo, no existe acuerdo doctrinal sobre lo que el mismo implica, aunque debe anotarse que sí hay unanimidad o, por lo menos, un extensísimo consenso sobre que el desistimiento no requiere ser "espontáneo", en cuanto que el mismo supondría "la existencia de una motivación 
puramente intrapsíquica que el legislador no exige" (ídem, p. 195) ${ }^{16}$. Pero qué debe entenderse por "abandono voluntario" es un interrogante al que se han aproximado los doctrinantes desde dos perspectivas distintas, a saber, las teorías psicológicas y las teorías normativas.

1. Teorías psicológicas. Un sector doctrinario estima que la voluntariedad del desistimiento se asemeja a la propia del dolo, de modo que sería voluntario todo desistimiento que obedezca a la "propia o autónoma decisión del agente, lo cual excluye de forma necesaria las circunstancias fácticas de orden externo e insuperable que obligan o imponen a la persona la voluntad de desistir". Según esta tesis "basta por consiguiente que el agente esté motivado por sí mismo, por su propia razón, de forma libre, sin que sea menester entrar a definir los motivos que lo llevaron a tomar esta determinación. Conforme a esto último es suficiente entonces que esté presente un motivo interesado o incluso 'aberrante al sentido jurídico"' (ARAQUE MoReno. Op. cit., p. 108).

En general, las teorías psicológicas son el criterio mayoritario seguido por los penalistas: entre los alemanes, se cuentan entre sus defensores FRANK, M. E. MAYER, Liszt-Schmidt, Allfeld, Mezger, Jagusch, Welzel y Baumann (Muñoz Conde. Op. cit., p. 84); contemporáneamente, la sostienen LACKNER, KÜHL y JESCHECK ${ }^{17}$. Esta tesis también es mayoritaria entre los penalistas colombianos, como puede constatarse en las obras de ReYes Echandía (Op. cit., p. 195), Fernández CARRASQuilla (1989, p. 376), Velásquez Velásquez (2009, p. 971) y Córdoba Angulo (Op. cit., p. 71).

Ahora bien, ¿cuándo se considera que el desistimiento es voluntario y no obedece a "circunstancias fácticas de orden externo e insuperable"? Una alternativa doctrinal para resolver este problema consiste en descartar como voluntario todo desistimiento que se dé cuando el agente ha perdido el poder de consumar el delito, de modo que siempre que el agente desista, pese poder llevar a feliz término su plan, se debe reconocer la impunidad de su conducta. Esta tesis, sostenida por FRANK en sus comentarios al $\mathrm{StGB}^{18}$, es defendida en nuestro medio por CóRDOBA ANGULO (Op. cit., p. 71). Los tribunales alemanes, por su parte, consideran voluntario todo desistimiento cuando la opción por abandonar la consumación es uno de los distintos móviles a disposición del agente y no el único "móvil psíquico forzoso" (ARAQUE Moreno, Op. cit., p. 110).

16 En contra, Luis Eduardo Mesa Velásquez (1974, pp. 158 y 159).

17 “... el concepto de voluntariedad hay que determinarlo desde una perspectiva puramente 'psicológica' y no ética. De ahí que el desistimiento con efecto liberador de la pena también deba afirmarse, por ejemplo, si se desiste de matar a una víctima para hacerlo con otra" (JESCHECK. Op. cit. p. 584 y 585).

18 Comentario II al § 46: "El desistimiento es voluntario cuando el autor se dice a sí mismo: no quiero alcanzar el objetivo aunque podría hacerlo; no lo es si el autor se dice a sí mismo: no puedo alcanzar el objetivo aunque quisiera" (citado por JESCHECK, Op. cit., p. 585). 
En contra de las teorías psicológicas se han elevado algunas críticas, sintetizadas como sigue por MAURACH (Op. cit., p. 103):

Desde siempre se ha reprochado a esta concepción el que ella presupone una autodeterminación autónoma no comprobable del ser humano y un grado inconmensurable de libertad de cualquier coacción psíquica, con lo cual además de privilegiar al delincuente inescrupuloso, que no conoce la presión espiritual de intensos remordimientos de conciencia.

De la cita transcrita se deducen dos críticas fundamentales. En primer lugar, contra la fórmula de FRANK se aduce que se trata de un criterio subjetivo de difícil demostración, por referirse a los procesos mentales internos del agente (ARAQUE MORENO, Op. cit., p. 111); ahora bien, esta crítica también tendría que hacerse extensiva a toda teoría del delito que tome en consideración dispositivos subjetivos, como el elemento volitivo del dolo. Por lo tanto, desde una perspectiva más o menos tradicional de la teoría del delito, la cual se compagina cabalmente con el texto del derecho positivo colombiano -el cual hace numerosas referencias a elementos subjetivos-, esta crítica no genera mayor interés.

En segundo lugar, se critica a la fórmula de FRANK el implicar una "laguna de punibilidad" frente a los delincuentes motivados por razones altamente reprochables, pues en muchas ocasiones se podría estimar "voluntario" un desistimiento malicioso, pese a existir la posibilidad de consumación ${ }^{19}$. Ténganse por ejemplos los traídos a colación por Mir PUig (1996, p. 351): "El ladrón deja de tomar el dinero de la caja, aunque podría hacerlo, porque oye llegar a la Policía; el sujeto deja de disparar a la víctima al entrar la Policía, pese a que aún podría matar a aquélla". Para corregir este vacío, la jurisprudencia alemana modificó la fórmula de FRANK, "exigiendo que el sujeto pudiera racionalmente, según la experiencia, llegar a la consumación”, restricción que varios autores han estimado inadecuada ${ }^{20}$. En cualquier caso, la inclusión del criterio de razonabilidad para la determinación de lo voluntario psicológicamente ha llevado a recurrir a la casuística para resolver este asunto, para lo cual los autores han recurrido a algunos ejemplos jurisprudenciales:

Es voluntario el desistimiento que tiene lugar por razones de conciencia (...), por pudor $(\ldots)$, por miedo a la pena $(\ldots)$, por pánico $(. .$.$) , a causa del mal$ sabor de los medios abortivos (...) o por los insistentes reproches del coautor (...). Es involuntario el desistimiento motivado por el miedo a un descubrimiento inminente (...) o por haberle sido impedida la retirada al autor (...).

19 Vid. Diego Araque Moreno (Op. cit., p. 113) y Francisco Muñoz Conde (Op. cit., p. 88).

20 Vid., v. g., Santiago Mir Puig (Op. cit., p. 351). Conforme con la restricción se muestra HansHEINRICH JESCHECK (Op. cit., p. 585). 
En el supuesto de inhibiciones psíquicas depende de si poseen una naturaleza forzosa (JESCHECK, Op. cit., p. 585 y 586).

2. Teorías normativas. Estas teorías, escasamente seguidas en Colombia ${ }^{21}$, ofrecen parámetros para decidir valorativamente el carácter voluntario del desistimiento, restando relevancia al dato del querer como elemento ontológico.

La más notoria de estas teorías fue formulada por RoxiN ${ }^{22}$, para quien solo puede existir desistimiento voluntario cuando el agente obra en contra de "las reglas de la profesión criminal". En otros términos, si el sujeto activo desiste por una razón propia de la lógica del delincuente, tales como pretender eludir la acción de la justicia, asegurar el provecho de su actuar, etc., debe estimarse que el desistimiento no es voluntario, pues no merece recompensa quien obra de manera maliciosamente calculada ante el desistimiento y tan solo está acomodándose a la situación. En cambio, quien por ejemplo se ve asaltado por miedo intempestivo sin motivo concreto o explicable, estaría actuando irrazonablemente desde la perspectiva profesional del criminal, luego su desistimiento sería "voluntario"23.

Esta tesis de Roxin ha sido objeto de serias críticas. En primer lugar, no es claro si la referencia a lo "razonable para el delincuente" es un criterio subjetivo u objetivo, es decir, relativo al agente en cuestión o a la "lógica delincuencial" en general. Ahora bien, si el criterio es subjetivo, cada delincuente tendrá una manera distinta de pensar y lo que es "voluntario" para el uno por estar fuera de la lógica de su profesión, perfectamente podría ser racional para otro y, por lo tanto, no ser "voluntario", generando consecuencias inaceptables político-criminalmente. Por otro lado, si el criterio es objetivo, se estaría recurriendo a un "tipo ideal de delincuente", propio de un derecho penal de autor y, por lo tanto, inadmisible contemporáneamente (MUÑOZ COnde, Op. cit., pp. 93 y ss.).

21 Entre los textos didácticos de mayor uso, solo parece adherir a ella JuAn CARLos Ferré Olivé et al. (2010, p. 560).

22 Sobre la teoría normativa de JAKOBS, cfr. GÜNTHER JAKOBS (Op. cit., p. 344 y 345 ) y Diego ARAQUE Moreno (Op. cit., p. 118 y ss.). Sobre otras teorías valorativas, vid. CHRISTIAN JäGER (2003, p. 21 y ss.).

23 "El concepto de voluntariedad, al que se vincula la impunidad del desistimiento, hay que interpretarlo, por tanto, normativamente y desde luego desde el punto de vista de la teoría de los fines de la pena. Si alguien baja el brazo que ya tenía levantado para asestar el golpe mortal, porque en el último momento no se atreve a matar a su víctima, para afirmar la voluntariedad de ese desistimiento no interesa la cuestión, las más de las veces insoluble, de si el (sic) sujeto que desiste le hubiera sido posible psíquicamente seguir actuando. Lo decisivo es más bien que el desistimiento se presente como irracional según el criterio del operar delictivo y que con ello aparezca desde el punto de vista legislativo como retorno a la legalidad. Si éste es el caso, como sucede en mi ejemplo, debe afirmarse siempre la voluntariedad" (Roxin. 1972, p. 72). Vid., con referencias, Claus RoXIN (1976, pp. 253 y ss.) y Francisco Muñoz CONDE (Op. cit., p. 87). 
Por esta razón, la tesis de Roxin y las de otros autores que han tratado de llenar las supuestas lagunas de punibilidad de las teorías psicológicas con criterios que califiquen la "buena" y la "mala" voluntad, han sido acertadamente denunciadas por ZAFFARONI (Op. cit., p. 490 y 491) como contaminadas de elementos éticos ajenos a un derecho penal liberal:

Las dificultades para resolver algunos casos límites han llevado a la doctrina a inclinarse peligrosamente por una etización del desistimiento estimado como ‘voluntario' sólo mediante un ‘acto de valoracion' jurídica de contenido ético... No negamos que el desistimiento puede responder a motivaciones que aparezcan como aberrantes al sentimiento jurídico, pero creemos que ello no hace a la 'voluntariedad' del mismo, la que no puede negarse con fundamento en tales consideraciones, al menos frente al texto expreso de nuestra ley penal. Ni las dificultades para determinar la 'voluntariedad' del desistimiento, ni el sentimiento de rechazo que puedan producirnos algunas motivaciones, son suficientes para negarlo en base a consideraciones que son completamente ajenas al planteamiento y que, en definitiva, son argumentaciones propias de la culpabilidad de autor, y, lo que es aún peor, son verdaderas negativas de la relevancia del desistimiento fundadas en tipos de autor ${ }^{24}$.

Además, la tesis de Roxin adolece de serios vacíos de claridad, al referirse a un cuerpo completamente indeterminado de reglas, por cuanto no se puede afirmar que existan tipologías habituales para el comportamiento de todos los distintos infractores de la ley penal ${ }^{25}$.

Ante el desalentador panorama ofrecido por teorías normativas con tendencia "ética", autores como JESCHECK han tomado como punto de partida un criterio psicológico, adicionando algunos criterios normativos para eliminar los casos más protuberantes de lagunas de impunidad. En ese sentido puede entenderse también la tesis de ZAFFARONI, quien en principio defiende una tesis psicológica, pero incluye un criterio correctivo de carácter normativo para considerar no voluntario a ciertas formas de desistimiento. Tal criterio consiste en estimar que el desistimiento es "voluntario" cuando no está fundado en la representación de una acción especial del sistema penal y no está coaccionado por un tercero (ZAFFARONI, Op. cit., p. 489). Es decir, en aquellos casos que la motivación del delincuente está dada por la inminencia de una acción especial (entendida como "una especial vinculación del accionar del sistema con la conducta de tentativa, en el sentido de que no basta para descartar la voluntariedad del desistimiento la mera representación de la amenaza de pena o el temor genérico de ser descubierto") del sistema penal (es decir, de todo órgano o particular

24 En el mismo sentido, Araque Moreno (Op. cit. p., 121).

25 La crítica es de BottKe (citada por Christian JÄGer, Op. cit., p. 21). 
encaminado a frenar la actividad delictiva), no habrá lugar a estimar como voluntario al desistimiento. ZAFFARONI explica las consecuencias de su tesis como sigue:

Conforme a este criterio, no desiste voluntariamente quien lo hace ante la presencia de un policía o ante una alarma que le infunde temor. Poco importará que el policía no se percate siquiera de la ejecución ni del desistimiento, puesto que su sola presencia ya es una "acción especial" del sistema. Distinto es el caso en que el policía haya pasado sin notar nada, es decir que el peligro de ser descubierto haya pasado, al igual que si por accidente desconecta la alarma (...). En esos casos, si el sujeto desiste por temor, ya no lo hace en razón directa de una acción especial del sistema, sino por el genérico temor a ser descubierto, que la acción del sistema no ha hecho más que hacerlo actual y consciente.

Basta que la acción especial del sistema se dé en la representación del sujeto, sin que sea necesario que se corresponda con la realidad. Aunque la acción del sistema sea sólo imaginada por el autor, ya el desistimiento no será voluntario, como en el caso de quien cree que avanza un policía, cuando en realidad se trata de un asaltante disfrazado, o de quien confunde un simple reloj con una alarma.

Por supuesto que tampoco será voluntario el desistimiento de quien se ve obligado al mismo por la acción de un particular, aunque tenga la certeza de que no lo denunciará... (ZAFFARONI, Op. cit., pp. 489 y 490).

En cualquier caso, debe quedar claro que una "sana" o "loable" motivación no se requiere para estimar que un desistimiento es voluntario. En ese sentido se pronuncia la doctrina de manera casi unánime, recurriendo a algunos casos específicos. Así, dice Araque Moreno (Op. cit., p. 121) que "con este presupuesto debe quedar claro en primer lugar que habrá voluntariedad en situaciones de temor abstracto a la sanción penal (motivo interesado), satisfacción personal ante la humillación de la víctima (motivo éticamente reprochable), compasión, remordimiento, reproches internos o externos, vergüenza, lástima, razones espirituales de conciencia, etc. (motivos valiosos). Lo que decide en definitiva, al menos desde el punto de vista legal, no son pues los buenos, loables o plausibles motivos, pudiendo incluso -llegado el caso- ser razones éticamente reprochables y censurables las que determinen a favor de la existencia de la voluntariedad"26. En el mismo sentido se pronuncia ZAFFARONI: “... el desistimiento debe considerarse que es voluntario, únicamente cuando no se funda en la representación de una acción especial del sistema que pueda conducir a la punición o cuando el autor no actúa coaccionado por otro, sin que sea menester,

26 Un interesante intento por resolver grupos de casos recurriendo a las reglas propias del control de la voluntad en la autoría mediata se encuentra en JäGER (Op. cit., pp. 28 y ss.). 
en modo alguno, que el autor se funde en normas éticas o morales: el desistimiento voluntario puede estar fundado en un puro temor a la pena o en un cálculo especulativo (por ejemplo, que los beneficios que obtendría de abstenerse son mayores que los que pueda reportarle el delito)" (ZAFFARONI, Op. cit., p. 490). Por lo demás, la jurisprudencia colombiana ha sostenido esta misma tesis ${ }^{27}$.

\section{CUATRO REGLAS SOBRE LA VOLUNTARIEDAD DEL DESISTIMIENTO}

Parece, pues, que la doctrina se inclina a establecer un tipo de teoría normativa o, por lo menos, psiconormativa, para resolver el problema en cuestión. Esto resulta inevitable y la aceptación llana de una perspectiva psicológica entraña una dificultad insalvable. Aunque no comparto la crítica elevada a las teorías psicológicas sobre la complejidad probatoria de desentrañar los procesos psíquicos del agente (situación propia de toda indagación subjetiva $)^{28}$, es ineludible que una referencia jurídica a la efectiva voluntariedad de una conducta tiene que calificar ciertos motivos como válidos de cara a otros estimados como inválidos o, en concreto, "no voluntarios".

En efecto, al hablar de voluntariedad se puede hacer referencia fundamentalmente a dos acepciones: un comportamiento ha sido voluntario porque su actor ha decidido realizarlo o porque dicha decisión ha obedecido a un tipo de razón particular que no se estima, por cualquier razón, como un obstáculo a la autonomía. Así, cuando yo afirmo que "A ha tomado su paraguas porque está lloviendo", desde la primera acepción debo concluir necesariamente que A ha obrado voluntariamente, por cuanto él tomó la decisión respectiva. Si afirmo, en cambio, que "A no ha tomado su paraguas, pese a que está lloviendo (y lo sabe)", debo decir que la conducta fue igualmente voluntaria. En esta acepción, para estimarse que se ha obrado voluntariamente basta con aducir que se ha obrado por una razón. Ahora bien, esta acepción resulta absolutamente inútil para explicar lo que está en juego en el requisito de la voluntariedad del desistimiento, porque desde esta perspectiva toda conducta humana es por definición voluntaria y el requisito normativo, precisamente, pretende separar un grupo de casos de otro. Ciertamente, en un caso paradigmático de tentativa punible, en el cual el agente de un delito es sorprendido por las autoridades y amenazado por

27 CSJ. Sala de Cas. Penal. Sentencia de 17 de julio de 2003, radicado 18768.

28 Vale adicionar a la crítica tradicional la siguiente posibilidad: aparentemente sería imposible demostrar que un acto podía realizarse pero no se ha realizado, cuando, precisamente, se afirma que la no realización se debió a la ausencia de un elemento motivacional, mas no a que no se cuente con la habilidad y la oportunidad correspondiente: si afirmo que Pedro podía tocar el piano en un momento y lugar determinado, en el cual contaba con todos los medios necesarios, pero no quiso, parece que no tengo manera de probar que efectivamente podía y solo puedo especularlo. Esto es incorrecto, porque en esta acepción la expresión "X puede a" es solo una afirmación categórica sobre una habilidad y una oportunidad. Al respecto, cfr. AlF Ross (1975, pp. 164 y ss.). 
estas para que se detenga, desde esta acepción no existe ninguna objeción para decir que el agente detuvo su actuar voluntariamente para evitar un mal (la aprehensión física o, incluso, la muerte). Puesto que la primera acepción de conducta voluntaria equipara a esta con la conducta "decidida", finalmente desemboca en una definición de "conducta" y, por lo tanto, es incapaz de distinguir un grupo de casos de otro ${ }^{29}$.

Por esta razón, una fórmula que simplemente estime como voluntario el comportamiento que "pudo haber sido de otra forma" tiene que decir que todo comportamiento es voluntario, luego las teorías llanamente psicológicas son claramente insuficientes para cumplir el rol de diferenciación al que el requisito de la voluntariedad invita, pues ni siquiera en los casos de coacción podría establecerse que hubo desistimiento voluntario: al analizar su razonamiento práctico, quien es víctima de la llamada coacción "insuperable" siempre puede optar por sufrir las consecuencias con las que se le amenaza y, de esa forma, "superar" la coacción. Por lo tanto, la voluntariedad no puede consistir en que haya habido una razón para actuar cualquiera, sino que la razón en cuestión haya sido "válida".

En este sentido, resulta conveniente invocar la ambigüedad que, según Raz, existe cuando se hace referencia a las razones para actuar: a veces aludir a una razón para actuar puede significar hablar de la explicación causal de una decisión de conformidad con los cálculos hechos por un agente, pero también puede significar un hecho de acuerdo al cual se explica, evalúa o guía un comportamiento. Esta diferencia se ejemplifica fácilmente cuando se piensa en una falsa creencia para ejecutar una acción en el segundo sentido, que arrastra al uso del término en el primero: si digo "la razón de A para usar un abrigo es que creyó que haría frío" y fue el caso que no hizo frío, estoy usando el término "razón" como una explicación de la creencia de A, pero no como un hecho que deba guiar el comportamiento (un abrigo se debe usar porque hace frío, no porque se crea que hace frío $)^{30}$. Así, el ejercicio debe buscar no el he-

29 Si obrar voluntariamente es poder decidir, el mero vivir es obrar voluntariamente. Téngase como ejemplo de este uso de la palabra voluntariamente el siguiente pasaje: "Nuestro mundo es la dimensión de fatalidad que integra nuestra vida. Pero esta fatalidad vital no se parece a la mecánica. No somos disparados sobre la existencia como la bala de un fusil, cuya trayectoria está absolutamente predeterminada. La fatalidad en que caemos al caer en este mundo -el mundo es siempre éste, éste de ahora- consiste en todo lo contrario. En vez de imponernos una trayectoria, nos impone varias, y, consecuentemente, nos fuerza... a elegir. ¡Sorprendente condición la de nuestra vida! Vivir es sentirse fatalmente forzado a ejercitar la libertad, a decidir lo que vamos a ser en este mundo. Ni un solo instante se deja descansar a nuestra actividad de decisión. Es, pues, falso decir que en la vida «deciden las circunstancias». Al contrario: las circunstancias son el dilema, siempre nuevo, ante el cual tenemos que decidirnos. Pero el que decide es nuestro carácter" (OrTEGA y Gasset, 2006, p. 114).

30 "... people are to be guided by what is the case, not what they believe to be the case. To be sure, in order to be guided by what is the case a person must come to believe that it is the case. Nevertheless it is the fact and not his belief in it which should guide him and which is a reason... If reasons are to serve for guiding and evaluating behaviour then not all reasons are beliefs. It may seem that reasons which are neither the beliefs nor the desires of the agent cannot be used in explaining his behaviour, 
cho de que haya habido o no una explicación a la conducta voluntaria -que siempre se encontrará y colapsaría en que todo desistimiento es voluntario-, sino en torno a dividir entre las posibles razones para actuar aquellas que son "válidas" de las que no lo son propiamente, entendiendo que cuando la ley penal habla de voluntariedad lo hace aludiendo a un concepto que no equivale al de decisión.

Ahora bien, aunque esto significa que toda teoría capaz de dar sentido pleno a la idea de voluntariedad es, de alguna u otra manera, normativa, de aquí no se sigue la adopción de una explicación que solo entienda como voluntarios los actos de desistimiento motivados por razones éticas, humanitarias o, de una u otra manera, "loables". Por el contrario, como se explicará a continuación, debe estimarse que, por regla general, la mayoría de motivos para desistir son constitutivos de "voluntariedad" y solo excepcionalmente puede decirse que ciertos motivos carecen de esa capacidad.

De cara al Derecho penal colombiano, cualquier consideración normativa para determinar el alcance de la voluntariedad del desistimiento debe respetar una serie de puntos medulares que no pueden ser sacrificados, en aras de llenar las mal llamadas lagunas de punibilidad ${ }^{31}$ que surgen frente a casos intuitivamente chocantes de no punibilidad de tentativas desistidas voluntariamente. Como base ineludible no puede perderse de vista que, a la hora de ofrecer un criterio normativo para limitar o comprender los modos en los que se debe encauzar el requisito de la voluntariedad, es necesario determinar cuál es la justificación de la no punición del desistimiento, porque el alcance de los requisitos del desistimiento válido depende de la razón de ser de tal validez. Este punto, sin embargo, entraña algo más que la simple escogencia de una de las teorías mencionadas al comienzo del trabajo, por cuanto la justificación de la no punición del desistimiento es por definición positiva y contingente y no se puede especular sobre ella de antemano; en otras palabras, no todo sistema jurídico tiene que, por necesidad, no sancionar el desistimiento por la misma razón que otro (por lo demás, no todo sistema necesariamente condona el desistimiento). Es perfectamente imaginable un sistema jurídico en el cual la razón de ser del desistimiento fuera, por ejemplo, la recompensa al comportamiento ético, en cuyo caso solo se podría estimar como voluntaria la tentativa desistida que estuviera calificada

but this is a mistake. The explanation depends on his belief that the reasons obtain, but again this does not establish that his belief is the reason. All it shows is that this type of explanation of a person's behaviour turns on his beliefs that certain reasons apply rather than on the fact that they do apply. We can understand his behaviour even if we think he was wrong in believing that there were good reasons for him to do what he did" (RAZ, 1975, p. 17).

31 De conformidad con el principio de legalidad, en materia penal todo aquello que no esté expresamente prohibido está permitido, luego por definición no existen lagunas propiamente dichas sino ideológicas o de iure condendo. Solo puede hablarse de lagunas de punibilidad cuando se afirma que algo debería estar prohibido, discusión que no tiene cabida a nivel dogmático sino que es de exclusivo resorte legislativo o político-criminal. Por lo tanto, todo esfuerzo interpretativo por llenar "lagunas de punibilidad" tiene el carácter de suponer, paradójicamente, que bajo cierta lectura de la normatividad la tal "laguna" no existe, sino que es un error de los intérpretes que la suponen. 
por ciertos motivos particulares. Semejante justificación no es de esperarse en los derechos contemporáneos ${ }^{32}$, pero el ejemplo sirve para reencauzar la discusión a una solución apropiada ligada a la justificación real de las instituciones en cuestión y no a una hipotética justificación teórica, sin importar cuán coherente o atractiva sea.

En efecto, para conocer la justificación de la no punición del desistimiento es absolutamente insuficiente optar por una teoría razonable entre el catálogo que ofrece la doctrina, por cuanto una teoría de ese tipo puede referirse a una de dos cosas: o es una explicación de la política criminal positiva -es decir, efectivamente existentedentro de un sistema o es una justificación de una hipótesis extrajurídica de "ética punitiva". De este último caso no podría derivarse ningún tipo de consecuencia para hablar de la extensión del derecho positivo, como consecuencia del principio de legalidad; pero en aquel no bastaría con determinar la razonabilidad interna de la teoría, sino que sería aún menester explicar su capacidad de dar razón de la política criminal positiva. Este último procedimiento solo puede llevarse a cabo a través del establecimiento de lo que pretendió el legislador histórico de las normas penales, de la lectura de lo plasmado efectivamente en el derecho positivo y de su estudio sistemático con el grueso de principios que orientan los pilares del sistema.

Ese examen total es ajeno al alcance de este texto. Sin embargo, hay dos aspectos del ordenamiento jurídico positivo, con los cuales deseo concluir este trabajo, que pese a ser aparentemente triviales, son ineludibles para construir una teoría normativa: el principio de legalidad y la regulación del artículo 27, por un lado, y el mecanismo de motivación indirecta que ofrece la ley penal, por el otro, imponen dos criterios medulares y, por lo menos, cuasisuficientes para la determinación de la voluntariedad propia del desistimiento válido.

Una última aclaración: parece ser cierto, como lo afirma ARAQUE MORENO, que para determinar los casos de voluntariedad en el desistimiento no se cuenta con "reglas mágicas o sacramentales aplicables con igual rigor y precisión a todos los supuestos" (ARAQue Moreno. Op. cit., pp. 123-124). De conformidad con ello, los dos criterios aquí presentados no ofrecen una respuesta total a la infinita casuística disponible en la realidad y en la doctrina. Sin embargo, considero que las reglas que se siguen de estos criterios sirven para resolver la mayoría de los casos difíciles y de ellos se pueden derivar principios y grupos de casos ulteriores. En cualquier caso, debe rechazarse la creencia de que la referencia a "mirar las circunstancias de cada caso" equivalga a que la voluntariedad del desistimiento dependa de meras "intuiciones jurídicas" o afirmaciones arbitrarias sobre lo que en esta o aquella circunstancia parezca ser o no voluntario. En realidad, como se explicará a continuación, el conjunto

32 No obstante, a pesar de sonar como una hipótesis extraordinaria, cláusulas de este tipo aparecen habitualmente en nuestro ordenamiento penal. Así, téngase por ejemplo la menor punibilidad de ciertos delitos en atención a móviles "nobles". 
del ordenamiento jurídico ofrece algunos límites más o menos precisos sobre qué casos constituyen desistimiento voluntario.

1. Legalidad y lenguaje ordinario. La médula de la política criminal colombiana está dada por el principio de legalidad y sus corolarios. Por lo tanto, debe partirse de que la regulación del desistimiento se deriva de la referencia que hace el artículo 27 del CP a que la tentativa solo es punible cuando la consumación no se produce por circunstancias ajenas a la voluntad del agente. De los artículos 10 del CP, 28 del CC y del resto del andamiaje que constituye el eje liberal de nuestro ordenamiento penal se sigue que la ley debe entenderse en términos generales según las reglas del lenguaje ordinario y en un sentido más o menos natural del habla corriente de los destinatarios. Por lo tanto, en principio, cualquier referencia a "buenos motivos" o a un comportamiento ejemplar por parte del agente que desiste está simplemente excluida de la fórmula. En efecto, en el habla cotidiana no existe ninguna acepción en la que actuar por motivos abyectos o incluso por apetitos o inclinaciones naturales se considere obrar de manera "involuntaria" 33 . Por el contrario, el funcionamiento mismo de los juicios de reproche que se elevan en contra de quien actúa por motivos incorrectos se fundamenta, precisamente, en una referencia a la voluntariedad de quien actúa de conformidad con ellos ${ }^{34}$.

Pero igualmente queda excluida de la fórmula una acepción que equipare voluntad con la capacidad de decisión (esto es, una acepción en la que "X puede a" signifique llanamente que $\mathrm{X}$ tiene la habilidad y la oportunidad para hacer a) y que considere, por ejemplo, que quien actúa bajo coacción lo hace libremente ${ }^{35}$. El habla corriente, efectivamente, acoge un sentido de voluntariedad en el que se estima que quien obra por la razón prudencial de evitar un mal inminente de ciertas características no lo hace "voluntariamente", sin importar que en su análisis práctico el agente haya optado libremente por evitar el mal correspondiente. Así, en el habla ordinaria tiene sentido afirmar dos proposiciones aparentemente inconsistentes entre sí ante la siguiente situación:

Razón $x$ para hacer $\phi$ : A ha sido amenazado para que haga $\phi$

Razón $z$ para no hacer $\phi$ : A considera repulsivo hacer $\phi$.

33 Supongo que a esta realidad del lenguaje ordinario se refiere FERnÁNDEZ CARRASQUILLA (Op. cit., p. 376) al afirmar que "No se ve cómo el aplazamiento (...) o la malignidad de los motivos internos, podrían considerarse como 'circunstancias ajenas' a la voluntad del autor”.

34 No debe confundirse, en cualquier caso, la referencia a la voluntariedad con adhesión de cualquier tipo de doctrina metafísica sobre el libre albedrío. Al respecto, cfr. Alf Ross (Op. cit., pp. 101 y ss., especialmente 175 y ss.).

35 En este punto sigo de cerca el análisis que Ross (Op. cit.,pp. 159 y ss.) hace de la expresión "él podía haber actuado de otra manera". 
(1) A hizo $\phi$ y ha obrado de manera involuntaria (i.e., no ha podido hacer lo que quiere por la fuerza de la amenaza), al actuar de conformidad con la razón $x$.

(2) A no hizo $\phi$ y ha obrado de manera voluntaria (i.e., ha descartado la fuerza de la amenaza), al actuar de conformidad con la razón $z$.

Este sentido del habla es completamente extraño a una explicación analítica del razonamiento práctico, según el cual obrar de una u otra manera sigue siendo una decisión del agente que puede dar más o menos peso a las amenazas que se ciernen en su contra. No es consistente afirmar que quien opta por dar más peso a una razón que a otra actúa sin la voluntariedad de quien toma la decisión contraria, ni siquiera cuando una de las opciones es demostradamente superior; en efecto, no es correcto decir que quien obra por una amenaza no hace lo que quiere, por cuanto es evidente que el agente precisamente quiere evitar el mal con el que se le amenaza. Desde esta perspectiva, ajena al lenguaje corriente, debería concluirse siempre el actuar voluntario ante el dilema de una amenaza:

(1') Si A sigue la razón $x$ y hace $\phi$, optó voluntariamente por evitar el mal amenazado.

(2’) Si A sigue la razón $z$ y no hace $\phi$, optó voluntariamente a pesar del mal amenazado.

La aparente inconsistencia del lenguaje corriente entre (1') y (2') se debe a que en él la fórmula "voluntariamente", como se sigue de la explicación ofrecida al inicio de esta sección, no se refiere al razonamiento práctico del agente sino a una calificación de motivos: existen ciertos motivos frente a los cuales estamos dispuestos a dispensar al agente de su responsabilidad (positiva y negativa) frente a un hecho, al punto que juzgamos su comportamiento como si no hubiera respondido a ningún razonamiento práctico ${ }^{36}$. Tal es el caso de la llamada coacción y es en ese sentido que la hipótesis del numeral 8 del artículo 32 del CP (insuperable coacción ajena) dispensa

36 A este respecto resulta esclarecedor el análisis de Ross (Op. cit., pp. 171-172): "To be sure, we do say of a person under compulsion that 'he did not have any choice; there was only one thing to do.' But this is a manner of speaking which should not be taken literally. It actually says that the choice in the particular situation could be expected to lead only to one outcome according to ordinary human experience. Such is the case, for example, of a man who, under threat of death, is forced to act in a way that would lead to only minor harm to others. 'He had no choice' then is actually to say that the choice is regarded as obvious. Any normal person would under these circumstances, choose to save his own life. No one could expect anything else. Correspondingly, it must be recognised that the person under compulsion could have acted otherwise. A person who is forced by a revolver in his back not to shout a warning to his friends does in fact have it in his power to do so. He has both the ability and the opportunity to shout the warning: he can speak the language, he is not gagged, his friends are within hearing. The decision is thus entirely dependent upon his motivation ('will') and this is what we mean when we say that he could have acted otherwise". 
de responsabilidad penal, bajo el supuesto de que obrar en tales circunstancias libera al agente de un juicio negativo ${ }^{37}$. En lo que respecta al desistimiento, quien termina la ejecución de un delito bajo coacción no queda cobijado, igualmente, por el juicio positivo de responsabilidad que permitiría que su desistimiento se estimara como válido y que su conducta no fuera un delito tentado.

Ahora bien, la referencia a la calificación de motivos implica un ejercicio ulterior que refleja el que hasta aquí se ha adelantado, a saber, determinar dentro del cúmulo de razones para actuar cuáles de ellas se estiman como "coactivas" y, por ello, anuladoras de la voluntad. En este punto el lenguaje ordinario se vuelve un tanto insuficiente, por cuanto ciertos casos en los que parece poderse hablar de "coacción" no cabrían en los casos intuitivamente correctos de desistimiento voluntario (e.g., un agente detiene su actuar delictivo por temor a un castigo sobrenatural). Sin embargo, un caso específico parece claramente excluido y es el que genera mayores debates alrededor de las lagunas de punibilidad: en el habla corriente, la amenaza con un desenlace de violencia física anula la "voluntariedad" de un comportamiento. En las reflexiones que siguen solo me referiré a la coacción en este sentido específico, salvo que se indique lo contrario.

En conclusión, ninguno de los dos casos extremos reseñados se corresponde con fórmulas del lenguaje ordinario. "A solo actúa voluntariamente cuando lo hace de acuerdo a la moral" y "A actúa voluntariamente cuando lo hace por una amenaza" son fórmulas extrañas al lenguaje corriente y, por lo tanto, son desechables en la construcción del supuesto de hecho del desistimiento válido. Esta precisión preliminar, aunque sobremanera elemental, sirve para poner un coto a los dos extremos de la voluntariedad sin recurrir a una teoría normativa altamente comprometedora o caer en la circularidad de las teorías psicológicas; así, puede decirse llanamente que del texto legal se siguen dos reglas sobre la voluntariedad del desistimiento:

R1. Los agentes que desisten no requieren hacerlo por móviles axiológicamente calificados como buenos ${ }^{38}$.

R2. La coacción no es un móvil válido para desistir.

37 De conformidad con lo expuesto, debe anotarse que la "insuperabilidad" de la coacción no tiene nada que ver con la efectiva anulación de la voluntad y no debe tomarse literalmente, sino que debe interpretársele de acuerdo con estándares de expectativas. Así, AlF Ross (Op. cit., p. 173).

38 Téngase como posibles calificativos axiológicos la triada elemental de "bueno", "malo" e "indiferente". 
2. El miedo a la sanción. R2, sin embargo, debe ser calificada de alguna manera, para poder ser coherente con la manera en la que funciona el ordenamiento penal. Este opera, en efecto, a través de la creación de razones para la acción de carácter prudencial, tal y como se manifiesta en la idea de coacción psicológica que se sigue de la prevención general negativa a la que propende la pena. Ciertamente, la manera en la que el ordenamiento penal invita al cumplimiento de sus instrucciones es a través de amenazas punitivas, amenazas que se traducen en la efectiva coacción física en caso de incumplimiento por parte de los destinatarios.

Esto tiene una consecuencia importante para el derecho penal y para el caso que nos ocupa: en principio, el temor a la sanción penal es un motivo suficiente para cumplir la ley, tanto así que es el único que el ordenamiento ofrece. En otras palabras, mientras la ley penal no pontifique sobre la moralidad de la razón de ser de sus mandatos y no ofrezca juicios axiológicos para convencer a los destinatarios de su corrección, sino que, por el contrario, se limite a amenazar con la fuerza en caso de incumplimiento, se sigue que no hace ningún mal quien orienta su comportamiento por simple miedo a la violencia estatal.

Ahora bien, en lo que corresponde al desistimiento, esto genera una situación paradójica frente a R2: todo comportamiento jurídico-penalmente permitido es, desde la perspectiva del racionamiento práctico del agente, potencialmente producto de coacción legítima, pero de R2 se sigue que tal motivación no constituye "voluntariedad" en el caso del desistimiento. Esto genera una situación inaceptable: quien opta por no ejecutar ningún delito por temor a las sanciones, pese a su inclinación a delinquir si las sanciones no existieran, se comporta conforme a derecho; sin embargo, quien desiste del delito que ha principiado su ejecución, tendría que motivarse por algo distinto a la misma ley. Si hemos de aceptar que el derecho penal no pierde su autoridad durante la ejecución de un delito, su herramienta de convencimiento tampoco puede perderla; por lo tanto, R2 debe ser calificada en torno a aceptar la coacción de la ley como un motivo válido para desistir. Así las cosas, debe formularse una tercera regla:

R3. El temor a la amenaza abstracta de la ley no equivale a coacción en los términos de R2.

Es importante notar que la calificación de R3 se refiere a la amenaza abstracta de la ley, que es la que de conformidad con el sistema está llamada a motivar a los destinatarios de las normas. Por el contrario, cuando la actividad sancionatoria del Estado ya se ha puesto en marcha, la eventual coacción que hace desistir de la conducta criminal no se considera un motivo voluntario para el desistimiento válido. Por ejemplo, si A ingresa a una vivienda para hurtar distintos bienes y finalmente es acorralado por las fuerzas de policía, la cesación de su finalidad de cometer el delito no se puede estimar voluntaria. Esto se sigue de que en este caso la amenaza de la ley ya está en ejecución como respuesta a la tentativa y no es, desde ese momento, una 
mera amenaza sino la efectiva realización del mal advertido, anulándose el motivo de excepción de R3. Esto conlleva, no obstante, nuevas dificultades. Piénsese en el siguiente caso y sus distintas variantes:

C1. A entra a un supermercado y toma varios bienes de valor para apoderarse de ellos. Al disponerse a salir del lugar, ocurre que:

C1.1. A ve a un policía dentro del supermercado que luce sospechoso, por lo que se atemoriza y pone los bienes en su lugar.

C1.1.1. El policía no había advertido las actividades de A.

C1.1.2. El policía estaba tendiendo una redada a A.

C1.2. A ve un letrero que anuncia que el supermercado está vigilado con cámaras, por lo que se atemoriza y pone los bienes en su lugar.

C1.2.1. Los vigilantes del lugar no habían notado la presencia de A.

C1.2.2. Los vigilantes del lugar estaban esperando que A saliera del supermercado para capturarlo afuera del precinto en flagrancia.

En la variante C1.1.2 se aplica a cabalidad R2 sin la calificación de R3, a saber, el comportamiento coaccionado del agente no puede estimarse voluntario, por cuanto fue la efectiva realización de las amenazas legales el hecho que fungió como una razón para actuar en A. En C1.1.1, en cambio, no se había desplegado amenaza alguna, por lo que la coacción legal sigue siendo un motivo válido para actuar. Para resolver este caso, recurriendo a la solución ofrecida por ZAFFARONI (Op. cit. pp. 489 y 490) relativa a la acción especial del sistema, debería distinguirse si el agente de policía pasó "sin notar nada", caso en el cual el temor a la sanción es el temor genérico a ser descubierto, o si la presencia del policía equivalió a una "acción especial del sistema". La diferencia entre estos dos eventos parece, en realidad, artificial. En cualquier caso, el problema estriba en que, con independencia de lo efectivamente acaecido, el agente creyó que sí se había desplegado la amenaza y ese fue el motivo de su actuar, no la ley en abstracto (como lo sugiere ZAFFARONI y lo exigiría el correctivo de R3). Así, en C1.1.1 se presenta la siguiente situación: existen múltiples razones para motivar un desistimiento válido, pero se obró de conformidad con la creencia en una razón inválida (a saber, la realización de la amenaza estatal). De conformidad con las reglas hasta ahora postuladas, referidas a qué motivos constituyen voluntariedad, necesariamente debe haber una correspondencia entre las razones válidas y la creencia en las razones válidas ${ }^{39}$, luego se tendría que

39 Sobre la diferencia entre creer en una razón y una razón para actuar, vid. supra, n. 62. 
concluir que en C1.1.1 el desistimiento no fue voluntario. Sin embargo, parece ser posible incluir una cuarta regla que se deriva de otro principio político-criminal: en un derecho penal de acto inspirado liberalmente, es regla que el pensamiento no delinque (cogitationis poenam nemo patitur); por lo tanto, desistir por un motivo inválido cuyos elementos no se dan en la realidad es equivalente a la comisión de un crimen netamente putativo, de manera que negar la voluntariedad del desistimiento en ese caso contravendría la base político-criminal del sistema. Por lo tanto, se formula R4 como sigue:

R4. Desistir por una razón inválida putativa equivale a desistir voluntariamente.

Nótese que esta última regla no tiene la misma firmeza de las precedentes, por derivarse de un principio distinto. En efecto, R4 no afirma que en casos como C1.1.1 haya un desistimiento voluntario, sino simple y llanamente que tal acto es equivalente a que lo hubiera. Vale también notar que las manifestaciones de coacción que no se refieren a alteraciones físicas, como las creencias mágicas y supersticiosas, podrían en algunos casos ser subsumidas por R4, aunque por regla general deberían ser excluidas por otro principio.

Pasando a los casos C1.2, se presenta una situación compleja. En lo que corresponde a $\mathrm{C} 1.2 .2$, la respuesta es idéntica a la que se ofrece a C1.1.2, esto es, el desistimiento no puede ser válido. Pero a diferencia de los casos C1.1, aquí se trata del comportamiento de actores privados y no de la efectiva puesta en marcha de la acción de las autoridades. En principio, aquí no se puede aducir una diferencia importante entre la amenaza abstracta y la realización de la amenaza, por cuanto la mera amenaza por parte de terceros no es excluida por R3. Ello tiene sentido, porque la resistencia que ejercen los particulares (en especial las víctimas y los sujetos pasivos de los delitos) para que el agente desista son completamente ajenos al sistema motivacional del derecho penal.

Así las cosas, de conformidad con R2, la coacción por parte de la víctima o de terceros no puede constituir un móvil voluntario para desistir válidamente y, además, R3 no se aplica. Sin embargo, existe una similitud fáctica bastante protuberante entre C1.2.1 y C1.1.1, de modo que podría especularse que en C1.2.1 puede haber desistimiento válido por aplicación analógica in bonam partem de R4, aunque ese procedimiento solo puede proceder en un examen particular de cada caso.

De todas formas, se mantiene abierta la pregunta sobre si algún otro principio políticocriminal o norma efectiva del ordenamiento puede sustentar una respuesta que, por lo menos intuitivamente, exija tener un tratamiento distinto entre C1.2.1 y C1.2.2. Piénsese, por ejemplo, en un caso análogo a los eventos C1.2: 
C2. A ingresa a una vivienda para hurtar diversos bienes. Una vez adentro:

C2.1. Ve un letrero que dice "Cuidado - Perro bravo" y decide huir. En la casa no hay ningún perro.

C2.2. Ve un letrero que dice "Cuidado - Perro bravo" y decide huir antes de enfrentar al perro bravo que efectivamente está en la casa.

C2.3. Decide ignorar el letrero, pero el perro le ladra hasta que decide irse de la casa.

En C2, donde se recogen de alguna manera las posibilidades de C1.2, intuitivamente parece haber una diferencia relevante de los eventos en los que la motivación es putativa o referida a una razón efectiva (C2.1 vs. C2.2 y $\underline{\mathrm{C} 2.3}$ ) y aquellos en los que hay una diferencia entre una mera amenaza y la realización de la misma $(\mathrm{C} 2.1$ y C2.2 vs. $\underline{\text { C2.3 }}$ ). Correspondientemente, solo en C2.3 parece haber certeza de que el desistimiento no es válido, confirmando que el fundamento de R3 y R4 (por un lado, la diferencia entre amenaza y realización de la amenaza y, por el otro, la distinción entre razones putativas y efectivas) también parece valer para los casos en los que los particulares son quienes ejercen la coacción.

Aunque el planteamiento aquí realizado parece tener cierta consonancia con el andamiaje político-criminal del derecho penal colombiano, el ejercicio es por definición inacabado y demanda la inclusión progresiva de grupos de casos que funjan como topoi para orientar a los intérpretes. Con este modesto trabajo solo se ha pretendido ofrecer una alternativa normativa incipiente, sin caer en los compromisos supererogatorios de teorías que hacen referencia a órdenes cerrados, como las reglas de la profesión criminal, cuyos efectos convierten el desistimiento válido en un acto moral que no puede ser exigido por un derecho penal liberal.

\section{BIBLIOGRAFÍA}

Araque Moreno, Diego (2008). Desistimiento y Derecho Penal. Bogotá: Gustavo Ibáñez.

Córdoba Angulo, Miguel (2001). La tentativa. Bogotá: Universidad Externado de Colombia.

Cury Urzúa, EnRiQue (1992). Derecho Penal - Parte general. T. II. Santiago: Ed. Jurídica de Chile.

Fernández Carrasquilla, Juan (1989). Derecho Penal Fundamental. v. II. Bogotá: Temis. 
Ferré Olivé, Juan Carlos et al. (2010). Derecho Penal colombiano - Parte general. Bogotá: Ibáñez.

JäGER, CHRISTIAn (2003). "El elemento volitivo en el desistimiento de la tentativa Aportación para la asimilación de las Teorías de la Autoría y el Desistimiento", en Anuario de Derecho Penal y Ciencias Penales. T. LVI. Madrid.

JAKOBS, GÜNTHER (1997). "El desistimiento como modificación del hecho", en Estudios de derecho penal. Madrid: Civitas.

Jescheck, Hans-Heinrich et al. (2002). Tratado de Derecho Penal. Granada: Comares.

v. Liszt, Franz (1929). Tratado de Derecho Penal. v. 3. Madrid: Reus.

Maurach, Reinhart et al. (1995). Derecho Penal - Parte general. T. 2. Buenos Aires: Astrea.

Mayer, Max Ernst (2007). Derecho Penal-Parte general. Buenos Aires: B. de F.

Mesa Velásquez, Luis Eduardo (1974). Lecciones de Derecho penal. Bogotá: Universidad Externado de Colombia.

Mir Puig, Santiago (1996). Derecho Penal-Parte general. Barcelona.

Muñoz Conde, Francisco (1972). El desistimiento voluntario de consumar el delito. Barcelona: Bosch.

Ortega y Gasset, José (2006). La rebelión de las masas. Madrid: Espasa-Calpe.

RAZ, Joseph (1975). Practical Reason and Norms. Oxford: Oxford University Press.

Reyes Echandía, Alfonso (1981). La tipicidad. Bogotá: Universidad Externado de Colombia.

Ross, Alf (1975). On Guilt, Responsability and Punishment. Berkeley y Los Ángeles: University of California Press.

Roxin, Claus (1976). "Sobre el desistimiento de la tentativa inacabada", en Problemas básicos del derecho penal. Madrid: Reus.

Roxin, Claus (1972). Política criminal y sistema del Derecho penal. Barcelona: Bosch. 
SANCINETTI, MARCElo A. (1975). Fundamentación subjetiva del ilícito y desistimiento de la tentativa. Bogotá: Temis.

Sauer, Guillermo (1956). Derecho Penal (Parte general). Barcelona: Bosch.

Stratenwerth, Günter (s.f.). Derecho Penal-Parte general I. El hecho punible. Buenos Aires: Fabián J. Di Plácido Editor.

Velásquez Velásquez, Fernando (2009). Derecho Penal - Parte General. Medellín: Comlibros.

Welzel, Hans (1987). Derecho penal alemán. Santiago: Editorial Jurídica de Chile.

ZafFARONi, Eugenio RAúl (1982). Tratado de derecho penal-Parte general. T. IV. Buenos Aires: Ediar.

Zaffaroni, Eugenio Raúl et al. (2002) Derecho Penal - Parte general. Buenos Aires: Ediar.

\section{Jurisprudencia}

Corte Suprema de Justicia. Sala de Casación Penal. Sentencia de 17 de julio de 2003 , radicado 18768 . 